\title{
DETERMINAÇÃO DA ATIVIDADE ANTIBACTERIANA E TOXICIDADE DO ÁCIDO ACÉTICO E VINAGRES BRANCO E TINTO
}

\section{Determination of antibacterial activity and toxicity of acetic acid and white and red wine vinegars}

\author{
Iwa K. A. Utyama ${ }^{1}$; Denise de Andrade ${ }^{2}$; Evandro Watanabe ${ }^{3 *}$; Fabiana C. Pimenta ${ }^{4}$; Izabel \\ Y. Ito ${ }^{5}$ \\ ${ }^{1}$ Profa. Mestre do Departamento de Enfermagem da Universidade Estadual de Londrina; \\ ${ }^{2}$ Profa. Livre Docente do Departamento de Enfermagem Geral e Especializada da Escola de Enfermagem de \\ Ribeirão Preto-USP; \\ ${ }^{3}$ Prof. Doutor do Departamento de Ciências Básicas da Universidade Federal dos Vales do Jequitinhonha e \\ Mucuri; \\ ${ }^{4}$ Profa. Doutora do Departamento de Imunologia, Microbiologia, Parasitologia e Patologia do Instituto de Patologia \\ Tropical da Universidade Federal de Goiás; \\ ${ }^{5}$ Profa. Titular do Departamento de Análises Clínicas, Toxicológicas e Bromatológicas da FCFRP-USP.
}

*Autor para correspondência e-mail: evandrowatanabe@gmail.com

Recebido em 12/07/2007 - Aceito em 01/12/2007

RESUMO: O ácido acético e o vinagre têm longa história e aplicabilidade humana, incluindo o tratamento de feridas. $O$ objetivo deste estudo foi avaliar in vitro a atividade antibacteriana e a toxicidade do ácido acético e vinagres branco e tinto. A atividade antibacteriana foi determinada pela Diluição Inibitória Máxima (DIM) do ácido acético e dos vinagres frente às bactérias hospitalares: Pseudomonas aeruginosa (20), Escherichia coli (20) e Staphylococcus aureus (20), e a toxicidade obtida por meio do porcentual de mortalidade da Artemia salina Leach. As DIMs do ácido acético frente às $P$. aeruginosa, $E$. coli e $S$. aureus foram de 1:400. Além disso, os vinagres branco e tinto inibiram todas as E. coli e $S$. aureus a 1:50 e 1:33, respectivamente. No entanto, os vinagres tinto e branco apresentaram DIMs frente às $P$. aeruginosa de 1:67 e 1:50, respectivamente. $O$ ácido acético in natura, 1:50, 1:100, 1:200, 1:400 e 1:800 apresentaram toxicidade frente a $A$. salina Leach. Ambos os vinagres branco e tinto não mostraram toxicidade a 1:400 e 1:800. Em conclusão, é possível considerar que existe uma relação inversamente proporcional das diluições do ácido acético e dos vinagres, com a atividade antibacteriana e a toxicidade. Ainda, esse estudo fornece informações técnicas relevantes que podem servir de alerta acerca dos riscos do uso inadequado (diluição/concentração) desses produtos in vivo, especialmente, em feridas.

PALAVRAS-CHAVE: Ácido acético; Testes de Sensibilidade Microbiana; Toxicidade; Cicatrização de Feridas.

ABSTRACT: Acetic acid and vinegar have a long history and human applicability, including the clinical treatment of wounds. The aim of this study was to evaluate in vitro antibacterial activity and toxicity of acetic acid and white and red vinegars. The antibacterial activity was evaluated by Maximum Inhibitory Dilution (MID) of acetic acid and vinegars against hospital bacteria: Pseudomonas aeruginosa (20), Escherichia coli (20), Staphylococcus aureus (20), and the toxicity based on the mortality percentage of Artemia salina Leach. The MIDs of acetic acid against $P$.aeruginosa, E.coli and S.aureus were at 1:400. Moreover, the white and red vinegars inhibited all $E$. coli and $S$. aureus at 1:50 and 1:33, respectively. However, the red and white vinegars showed MIDs against $P$. aeruginosa at $1: 67$ and 1:50, respectively. The acetic acid in natura, 1:50, 1:100, 1:200, 1:400 e 1:800 demonstrated toxicity against $A$. salina Leach. Both white and red vinegars did not show toxicity at $1: 400$ and 1:800. In conclusion, it is possible to consider that there is an inverted proportional relation of the acetic acid and vinegars dilutions, with the antibacterial activity and the toxicity. Besides, this study provides some relevant technical information that can elucidate about risks of inadequate use (dilution/concentration) these products in vivo, specially, on wounds.

KEYWORDS: Acetic acid; Microbial Sensitivity Tests; Toxicity; Wound Healing. 


\section{INTRODUÇÃO}

O ácido acético $(\mathrm{CH} 3-\mathrm{COOH})$ conhecido popularmente como vinagre é resultante da fermentação (oxidação) do álcool etílico por ação da bactéria Acetobacter aceti. Tem longa história e aplicabilidade humana, incluindo a culinária, o tratamento de feridas ou lesões (verruga, calosidade, impetigo, furúnculo, queimaduras, picada de inseto), a terapêutica na endodontia, na pediculose, na otite, de processos inflamatórios da boca e garganta, o diagnóstico de neoplasias do cérvix uterino, a desinfecção de alguns artigos semi-críticos, dentre outras aplicabilidades (KRASIL'NIKOV et al., 1991; AMINIFARSHIDMEHR 1996; ANDREWS et al., 2003; MAZZOLA et al., 2003).

Especificamente, em relação ao uso de ácido acético ou vinagre em feridas há recomendação de aplicação tópica desses produtos diluídos em água fervida. Essa diluição parece minimizar a toxicidade tecidual sem, contudo alterar a sua atividade antimicrobiana, e, assim, contribuir no processo de cicatrização tecidual. Nesse sentido, alguns estudos a respeito da atividade antimicrobiana in vivo de vinagres comerciais têm sugerido diferentes diluições/concentrações de uso (PHILLIPS et al., 1968; SILVA et al., 2002; ANDREWS et al., 2003; MAZZOLA et al., 2003).

O vinagre é um produto natural, porém segundo OLIVEIRA \& GONÇALVES (2006) a idéia de que plantas medicinais e fitoterápicos são inócuos, "Natural, não faz mal", é uma realidade preocupante entre a população. Assim, são necessárias medidas efetivas que contribuam para o uso racional desses produtos que podem levar a sérias conseqüências, como intoxicações.

Acresce-se a problemática que na literatura são escassas as informações científicas quanto a Diluição Inibitória Máxima (DIM) e a toxicidade desses produtos. Assim, a aplicabilidade segura nos pacientes tem exigido a realização de pesquisas que avaliem tanto a atividade antibacteriana, quanto a toxicidade aos tecidos.

Neste sentido, questiona-se: Quais são as DIMs do ácido acético e dos vinagres capazes de inibir bactérias epidemiologicamente importantes no cenário das infecções hospitalares, e, simultaneamente serem atóxicas ao tecido? Frente ao exposto, objetivou-se:

- Avaliar in vitro as DIMs do ácido acético e vinagres branco e tinto frente às bactérias hospitalares;

- Determinar in vitro a toxicidade do ácido acético e vinagres branco e tinto frente a Artemia salina Leach.

\section{MATERIAL E MÉTODO}

Foram avaliados os seguintes produtos: Ácido Acético PA (Merck, São Paulo, SP, BR) e Vinagre de Vinho Branco Clássico e Vinagre de Vinho Tinto Clássico (CASTELO, Jundiaí, SP, BR) frente às bactérias hospitalares: Pseudomonas aeruginosa (20), Echerichia coli (20) e Staphylococcus aureus (20) isoladas de pacientes internados no Hospital das Clínicas da Faculdade de Medicina de Ribeirão Preto - USP (Comitê de Ética em Pesquisa $\left.n^{\circ} 7485 / 98\right)$.

Para a determinação da Diluição Inibitória Máxima (DIM) dos produtos foram realizadas diluições em duplicata (1:25, 1:33, 1:50, 1:67, 1:100, 1:200, 1:133 e 1:400) em tubos de ensaio (20x200mm). Após a realização das diluições, $18,0 \mathrm{ml}$ de meio de cultura Miller Hinton Agar (Oxoid, USA) fundido a cerca de $45^{\circ} \mathrm{C}$ foram adicionados aos tubos, e a solução resultante vertida em placas de Petri (20x100mm) esterilizadas.

As suspensões dos inóculos bacterianos com turvação da metade da escala 1 de McFarland foram realizadas em solução fisiológica a partir de culturas jovens $\left(37^{\circ} \mathrm{C}\right.$ por $\left.24 \mathrm{~h}\right)$. Após a solidificação dos meios de cultura com os produtos foi realizada a semeadura dos inóculos bacterianos com auxílio de um inoculador multipontual de Steers (STEERS et al., 1959).

Decorrido o período de incubação das placas a $37^{\circ} \mathrm{C}$ por $24 \mathrm{~h}$, a inibição do crescimento bacteriano na superfície do meio de cultura foi analisada e a DIM considerada como a maior diluição do produto capaz de propiciar a inibição do crescimento bacteriano (WADE \& ADDY, 1992).

Para a avaliação da toxicidade do ácido acético e dos vinagres branco e tinto foi utilizada a $A$. salina Leach, que é uma larva de camarão salmoura invertebrada.

Foram adicionadas $35 \mathrm{~g} / \mathrm{l}$ de sal marinho e o pH ajustado entre 8 e $9 \mathrm{com}$ a adição de $\mathrm{NaOH}$ a $0,1 \mathrm{~N}$. Essa solução foi utilizada para a eclosão dos ovos da $A$. salina Leach e a preparação das diluições dos produtos. Os ovos das lavas $(200 \mathrm{mg} / 400 \mathrm{ml})$ foram colocados para eclodir em solução salina com aeração constante e exposição à luz diurna por 48h. Os produtos foram diluídos em triplicata (1:50, 1:100, 1:200, 1:400 e 1:800). Em 
cada tubo de ensaio com as diluições dos produtos foram adicionadas 10 larvas. Decorrido o período de $24 \mathrm{~h}$ sob iluminação, as larvas sobreviventes foram contadas. O controle negativo utilizado para esse teste de toxicidade foi solução fisiológica.

Para o cálculo do percentual de mortalidade da $A$. salina Leach aplicou-se a seguinte fórmula:

$\%$ de mortalidade $=\underline{n^{0}-\text { de larvas mortas ou com inibição de movimento } \times 100}$ no total de larvas

Os resultados de $100 \%$ de mortalidade significam elevada toxicidade e de $0 \%$, sem toxicidade.

\section{RESULTADOS}

As DIMs e a toxidade do ácido acético e dos vinagres branco e tinto frente às bactérias hospitalares: $P$.aeruginosa (20), E.coli (20) e S.aureus (20), bem como a $A$. salina Leach estão apresentadas nas Tabela 1 e 2, respectivamente.

Tabela 1. Diluição Inibitória Máxima do ácido acético e dos vinagres branco e tinto frente às bactérias hospitalares: P.aeruginosa (20), E.coli (20) e S.aureus (20).

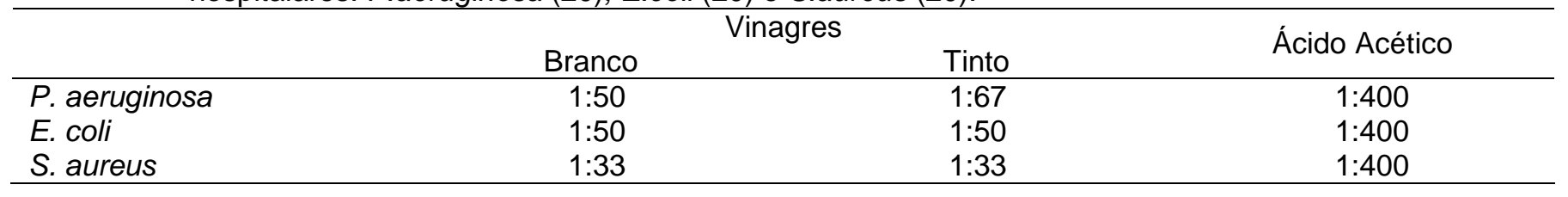

Tabela 2. Toxicidade do ácido acético e dos vinagres branco e tinto frente a $A$. salina Leach expressa em percentual de mortalidade das larvas.

\begin{tabular}{|c|c|c|c|c|}
\hline & \multicolumn{2}{|c|}{ Vinagres (\%) } & \multirow{2}{*}{\multicolumn{2}{|c|}{ Ácido acético \% }} \\
\hline & Branco & Tinto & & \\
\hline In natura & 100 & 100 & 100 & \\
\hline $1: 50$ & 100 & 100 & & 100 \\
\hline $1: 100$ & 100 & 100 & & 100 \\
\hline $1: 200$ & 100 & 100 & & 100 \\
\hline $1: 400$ & 0 & 0 & & 100 \\
\hline $1: 800$ & 0 & 0 & & 100 \\
\hline
\end{tabular}

$100 \%$ de mortalidade significa elevada toxicidade

$0 \%$ de mortalidade significa sem toxicidade

\section{DISCUSSÃO}

De um modo geral é possível considerar que existe uma relação inversamente proporcional das diluições do ácido acético e vinagres branco e tinto, com a atividade antibacteriana e a toxicidade.

Os vinagres branco e tinto inibiram todas as 20 cepas hospitalres de P.aeruginosa, nas diluições de 1:50 e 1:67, respectivamente. Ainda, as DIMs do ácido acético para $P$. aeruginosa, E. coli e $S$. aureus foram de 1:400, e estão de acordo com estudos, que evidenciaram a eficácia desse produto, principalmente, em feridas que haviam suspeita de infecção por Pseudomonas spp. (PHILLIPS et al., 1968; KRASIL'NIKOV et al., 1991; SLOSS et al., 1993; ARAÚJO et al., 1995; NAGOBA et al., 1997; SILVA et al., 2002). Merece destaque o estudo de ARAÚJO et al. (1995) que demonstraram a inibição in vitro de diferentes cepas de Pseudomonas spp., incluindo uma $P$. aeruginosa padrão (ATCC 27853), com ácido acético diluído a 1:400.

As DIMs dos vinagres branco e tinto frente a $E$. coli foram de 1:50, uma vez que o vinagre branco não foi capaz de inibir 4 das 20 cepas de E. coli na diluição de 1:67. No entanto, para o $S$. aureus as DIMs foram de 1:33 para ambos os tipos de vinagres. 
De acordo com Benassatti et al. (1994), o uso do acido acético na diluição de 1:200 mostrou atividade antibacteriana frente aos materiais semi-críticos contaminados com E. coli, $S$. aureus e $P$. aeruginosa.

Com relação ao provável mecanismo da atividade antibacteriana do ácido acético e dos vinagres, eles podem atuar principalmente na parede celular das bactérias. Nesse sentido, a comunidade científica reconhece que o principal componente estrutural da parede celular é um peptidioglicano (mureína), polímero misto de hexoses ( $\mathrm{N}$-acetilglicosamina e ácido $\mathrm{N}$-acetilmurâmíco) e aminoácidos. Nas bactérias Gram-positivas, no caso dos S. aureus, o peptidioglicano forma uma camada espessa $(20-80 \mathrm{~nm})$, tornando a parede insolúvel em álcool, bem como mais rígida e resistente à pressão do que as das bactérias Gram-negativas. Por outro lado, as bactérias Gram-negativas como as $P$. aeruginosa e $E$. coli são constituídas de uma parede celular com uma camada de peptidoglicano delgada $(5-10 \mathrm{~nm})$, mas com a presença de lipopolissacarídeos (LPS), lipoproteínas, proteínas e um canal para o transporte de nutriente e subprodutos denominado de porina (Figura 1).

Na Figura 1 observa-se os diferentes constituintes químicos presentes nas paredes celulares de bactérias Gram-positivas e de Gram-negativas. A parede celular de uma bactéria Gram-negativa é delgada, complexa, dissolve-se na presença de álcool e não suporta tanta pressão quanto uma bactéria Gram-positiva. Dessa maneira, como o ácido acético e o vinagre contêm álcool, essa pode ser uma das possíveis explicações do mecanismo de ação desses produtos nos componentes da parede celular. Ainda, pouco se sabe a respeito do mecanismo de ação do ácido acético e do vinagre contra as bactérias, no entanto pesquisadores suspeitam que a quantidade de proteína e/ou lipídio existente na parede celular possa interferir nessa atividade. Essas especulações merecem a realização de futuros estudos, sugerindo que esses produtos possam atuar mais nessa complexa parede celular das bactérias Gram-negativas do que das Gram-positivas.

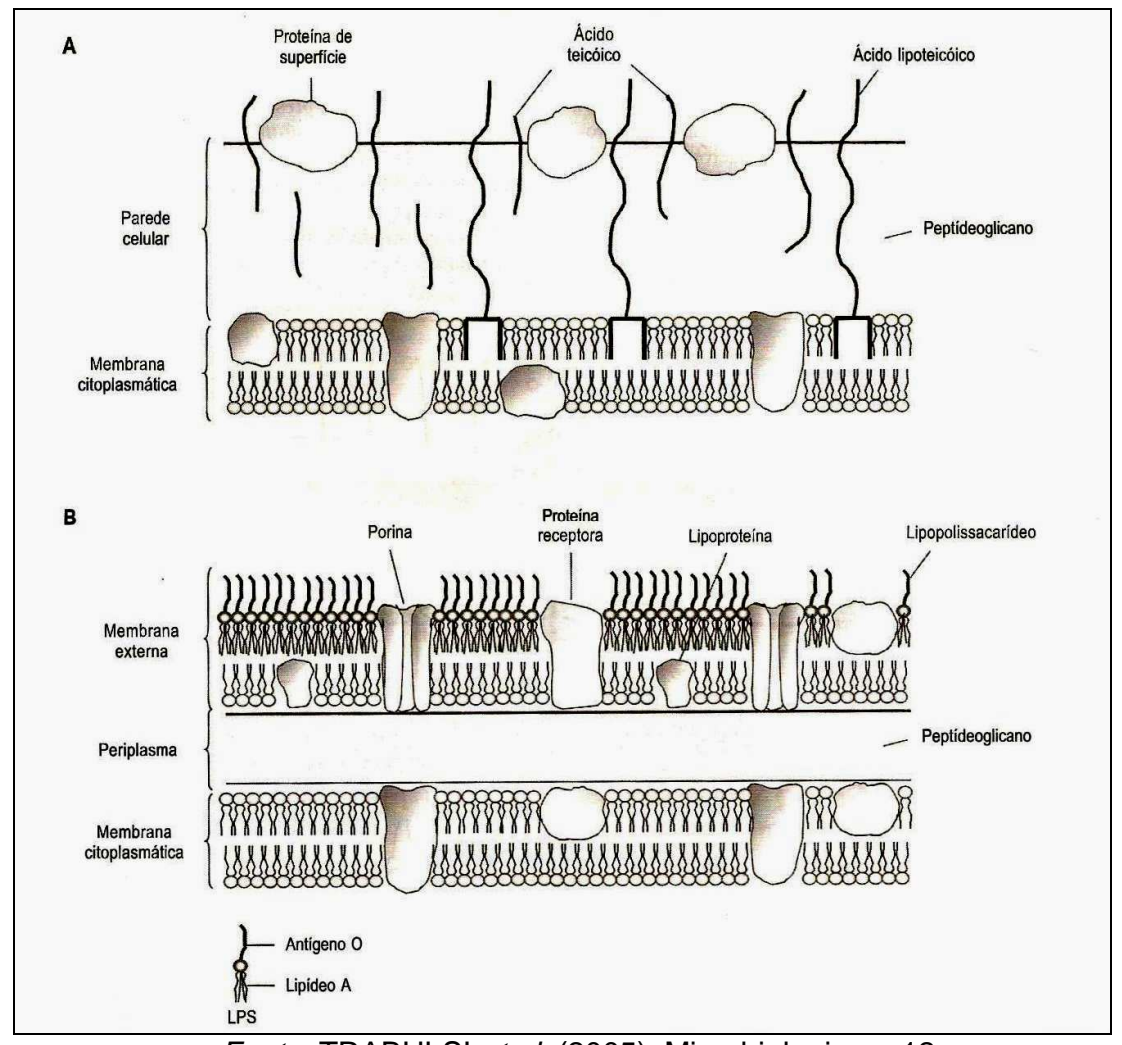

Fonte: TRABULSI et al. (2005). Microbiologia. p. 12.

Figura 1. Representação esquemática das diferenças estruturais entre as paredes bacterianas de Gram-positivas (A) e Gram-negativas (B).

Outro aspecto a considerar se reporta a toxicidade do ácido acético e do vinagre frente a $A$. salina Leach, que é uma larva de camarão salmoura invertebrada usada como teste alternativo para determinação da toxicidade e fototoxicidade de produtos naturais e sintéticos. Ela apresenta sensibilidade a substâncias tóxicas e é semelhante ao fibroblasto de humano. Além disso, essa técnica apresenta vantagens por ser de baixo custo, rápida e de fácil execução (LOGARTO et al., 2001; SANTOS et al., 2003).

Embora a eliminação total do uso de animais ainda não seja possível, a citotoxicidade basal in vitro tem sido empregada como adjuvante dos testes em animal para a seleção das doses iniciais (VALADARES, 2006).

Nesse estudo, o ácido acético mostrou ter elevada toxicidade até na diluição de 1:800. Por outro lado, os vinagres brancos e tinto nas diluições de 1:400 apresentaram toxicidade zero, no entanto as DIMs frente às 
bactérias hospitalares foram de 1:33, 1:50 e 1:67; até 12 vezes mais concentradas do que as diluições consideradas sem toxicidade (1:400).

Nossos resultados estão de acordo com os dos pesquisadores que avaliaram in vitro a toxicidade de diferentes antimicrobianos frente a fibroblastos de humanos, entre eles, o ácido acético a 1:400, que mostrou ser tóxico nessa diluição (LINEAWEAVER, et al., 1985).

Mckenna et al. (1991) concluíram que o ácido acético a 1:4.000 foi capaz de preservar a função do fibroblasto e inibir P.aeruginosa.

Vale reconhecer que o mecanismo de ação de biocidas é fortemente influenciado pela presença de um ou vários componentes ativos, culminando ou não em compatibilidades físico-químicas, que podem aumentam ou diminuir a atividade antimicrobiana.

Nesse sentido, Benavides et al. (1991) verificaram em epiderme de abdômen de rato que o ácido acético em diluições menores ou iguais a 1:29 danificaram somente 4,0 a 5,0\% das células e produziram pequenas reduções da matriz citoplasmática, com possibilidade de recuperação celular e tissular.

Esses resultados corroboram com os estudos in vitro de culturas de tecidos de humanos que demonstraram a menor toxicidade do ácido acético a 1:400 frente aos fibroblastos e queratinócitos, porém, sem atividade antimicrobiana. Além disso, um estudo in vitro com culturas de células Hep-2 (células de carcinoma da laringe de humano) e Vero (células de rins do macaco verde africano) verificaram que o ácido acético e o vinagre nas diluições de 1:20 a 1:200 e de 1:3 a 1:20, respectivamente, causaram efeitos citotóxicos, após incubação a 370 por 24h (SANKARANARAYANAN et al., 1999).

Diante da literatura acerca da toxicidade do ácido acético e do vinagre é passível de observar que os resultados são contraditórios.

Nesse estudo, os produtos analisados mostraram elevada toxicidade ( $A$. salina Leach) nas DIMs que poderiam ser usadas contra as bactérias hospitalares. Assim, novos estudos são necessários em modelo animal e até humano, com a finalidade de viabilizar futuramente a sua aplicabilidade in vivo, especialmente em feridas contaminadas e/ou infectadas, visto que esses produtos apresentam vantagens por serem biodegradáveis, de baixo custo e facilmente disponíveis.

Por isso, ainda que o estudo mencionado seja in vitro, acredita-se que só seja recomendável o uso do vinagre na diluição de 1:400 (sem toxicidade) e a não utilização do ácido acético nas diluições analisadas (até 1:800). Além disso, na área clínica merecem destaque os relatos dos pacientes quanto à ardência na aplicação tópica (feridas), que provavelmente pode estar associada com a danificação das células neoformadas.

\section{CONCLUSÃO}

É importante salientar que tanto o ácido acético quanto os vinagres branco e tinto têm sido utilizados como agentes antimicrobianos no tratamento de feridas, e algumas vezes em diluições inadequadas, o que conseqüentemente poderá causar danos aos tecidos, bem como dificultar o processo de cicatrização das feridas.

A nosso ver é premente despertar nos profissionais da saúde a consciência crítica-reflexiva em relação à utilização das evidências científicas de maneira que possam analisar e aplicar com critério os resultados das pesquisas em prol da qualidade da assistência à saúde.

Então, esse estudo fornece informações técnicas relevantes quanto as DIMs, e pode servir de alerta acerca dos riscos do uso inadequado (diluição/concentração) desses produtos in vivo, especialmente, em feridas.

\section{AGRADECIMENTO}

A farmacêutica e técnica do Laboratório de Microbiologia da FCFRP-USP, Maraisa Palhão Verri, pela valiosa colaboração na etapa do processamento laboratorial microbiológico.

\section{REFERÊNCIAS}

ANDREWS, K.; MOWLAVI, A.; MILNER, S. M. The treatment of alkaline burns of the skin by neutralization. Plastic and Reconstructive Surgery. v. 111, n. 6, p. 1918-1921, 2003.

AMINIFARSHIDMEHR, N. The management of chronic suppurative otitis media with acid media solutions. The American Journal of Otology. v. 17, n. 1, p. 24-25, 1996.

ARAÚJO, G. F.; BATISTA, J. E.; MONTEIRO-NETO, V.; ROCHA, A. M. F.; LIMA, L. A. M. Eficácia in vitro do ácido acético em Pseudomonas spp. Acta Cirúrgica Brasileira. v. 10, n. 4, p. 201-203, 1995. 
BENASSATTI, H. E.; MARFIL, L. M.; OCCHIONERO, M. Acido acético: su capacidad desinfectante. Acta Bioquímica Clínica Latinoamericana. v. 28, n. 3, p. 411-419, 1994.

BENAVIDES, J.; BENAVIDES, J.; GUERRERO, M.; BURBANO, R. El empleo del ácido acético como antiséptico: un enfoque racional. Revista Colombiana de Ortopedia y Traumatología. v. 5, n. 2, p.117-124, 1991.

KRASIL'NIKOV, A. P.; ADARCHENKO, A. A.; BULAI, P. I.; SOBESHCHUK, O. P. [A comparative analysis of the antibacterial activity of antiseptics and antibiotics on samples of Pseudomonas aeruginosa]. Zhurnal Mikrobiologii, Epidemiologii, i Immunobiologii. n. 8, p. 30-33, 1991.

LINEAWEAVER, W.; McMORRIS, S.; SOUCY, D.; HOWARD, R. Cellular and bacterial toxicities of topical antimicrobials. Plastic and Reconstructive Surgery. v. 75, n. 3, p. 394-396, 1985.

LOGARTO, P. A.; SILVA, Y. R, GUERRA, S. I.; IGLESIAS, B. L. Comparative study of the assay of Artemia salina $\mathrm{L}$. and the estimate of the medium lethal dose (LD50 value) in mice, to determine oral acute toxicity of plant extracts. Phytomedicine: International Journal of Phytotherapy and Phytopharmacology. v. 8, n. 5, p. 395-400, 2001.

MAZZOLA, P. G.; MARTINS, A. M. S.; PENNA, T. C. V. Determination of decimal reduction time (D-value) of chemical agents used in hospital disinfection. Brazilian Journal of Microbiology. v. 34 (suppl.1), p. 33-34, 2003.

TRABULSI, L. R.; ALTERTHUM, F.; MARTINEZ, M. B; CAMPOS, L. C.; GOMPERTZ, O. F.; RÁCZ, M. L. Microbiologia. São Paulo: Editora Atheneu, 2005.

McKENNA, P. J.; LEHR, G. S.; LEIST, P.; WELLING, R. E. Antiseptic effectiveness with fibroblast preservation. Annals of Plastic Surgery. v. 27, n. 3, p. 265-268, 1991.

NAGOBA, B. S.; DESHMUKH, S. R.; WADHER, B. J.; PATIL, S. B. Acetic acid treatment of pseudomonal postoperative wound infection. The Journal of Hospital Infection. v. 36, n. 3, p. 243-244, 1997.

OLIVEIRA, F. Q.; GONÇALVES, L. A. Conhecimento sobre plantas medicinais e fitoterápicos e potencial de toxicidade por usuários de Belo Horizonte, Minas Gerais. Revista Eletrônica de Farmácia. v. 3, n. 2, p. 36-41, 2006.

PHILLIPS, I.; LOBO, A. Z.; FERNANDES, R.; GUNDARA, N. S. Acetic acid in the treatment of superficial wounds infected by Pseudomonas aeruginosa. Lancet. v. 6, n. 1, p. 11-14, 1968.

SANKARANARAYANAN, R.; SHYAMALAKUMARY, B.; WESLEY, R.; SREEDEVI, A. N.; PARKIN, D. M.; NAIR, M. $\mathrm{K}$. Visual inspection with acetic acid in the early detection of cervical cancer and precursors. International Journal of Cancer. v. 80, n. 1, p. 161-163, 1999.

SANTOS, P. L. P.; PINTO, G. B, TAKAHASHI, J. A.; SILVA, L. G.; BOAVENTURA, M. A. Biological screening of Annonaceous Brazilian Medicinal Plants using Artemia salina (brine shrimp test). Phytomedicine: International Journal of Phytotherapy and Phytopharmacology. v. 10, n. 2-3, p. 209-212, 2003.

SILVA, M. R. L.; PEREIRA, D. A. S; LINHARES, R. E. C.; PELAYO, J. S. Ácido acético como tratamento alternativo para feridas contaminadas por Pseudomonas aeruginosa e seu efeito em células Hep-2 e Vero. Biosaúde; $4^{\text {nd }}$ ed. Especial 2002.

SLOSS, J. M.; CUMBERLAND, N.; MILNER, S. M. Acetic acid used for the elimination of Pseudomonas aeruginosa from burn and soft tissue wounds. Journal of the Royal Army Medical Corps. v. 139, n. 2, p. 49-51, 1993.

STEERS, E.; FOLTZ, E. L.; GRAVES, V. S. An inocula replicating apparatus for continue testing of bacterial susceptibility to antibiotics. Antibiotics and Chemotherapy. v. 9, p. 307-311, 1959.

VALADARES, M. C. Avaliação de toxicidade aguda: Estratégias após a "Era do teste DL50“. Revista Eletrônica de Farmácia. v. 3, n. 2, p. 93-8, 2006.

WADE, W. G.; ADDY, M. Antibacterial activity of some triclosan-containing toothpaste and their ingredients. Journal of Periodontology. v. 63, n. 4, p. 280-282, 1992. 